\title{
Diabetic retinopathy before and after cataract
} surgery

\author{
Marianne Henricsson, Anders Heijl, Lars Janzon
}

\begin{abstract}
Aims/background-Increased retinopathy progression has been reported after cataract surgery in patients with diabetes mellitus. To assess the influence of cataract surgery on visual acuity and retinopathy progression, all diabetic patients who were subjected to cataract surgery during 1991-3 have been followed up at the Department of Ophthalmology in Helsingborg. The average follow up time was 2 years.
\end{abstract}

Methods-One eye of each of 70 patients was included in the study, 35 monocularly and 35 binocularly operated on. Sixteen of the 70 patients had proliferative diabetic retinopathy (PDR) at baseline. The Wisconsin scale was used for the grading of retinopathy. The degree of glycaemic control was assessed by measurements of HbA $_{1 \mathrm{c}}$.

Results-Most patients obtained improved visual acuity; a postoperative visual acuity of 0.5 or better was achieved in $89 \%$ of diabetic surgical eyes. Progression of the retinopathy occurred in $\mathbf{3 0}$ out of the 70 eyes, and was associated with mean level of $\mathrm{HbA}_{1 \mathrm{c}}(p=0.04)$, duration of diabetes $(p=0.02)$, insulin treatment $(p=0.001)$, and presence of retinopathy at baseline $(p=0.01)$. Patients who progressed had a significantly higher incidence of macular oedema $(p=0.006)$ than those who did not progress. No significant differences were found when operated and non-operated eyes were compared in the 35 patients with monocular surgery. Two patients in this group, however, ended up with macular oedema and worse vision in the operated eye than in the eye which was not operated on. Both patients had background retinopathy before surgery. Conclusions-Patients in this study, also those with PDR, obtained good visual acuity, better than in most previous studies. Poor glycaemic control was a factor of importance for the progression of diabetic retinopathy after cataract surgery.

(Br F Ophthalmol 1996;80:789-793)

Community Medicine L Janzon

Correspondence to: Marianne Henricsson, $\mathrm{MD}$, Department of
Ophthalmology, Helsingborg Hospital, S-25187, Helsingborg, Sweden.

Accepted for publication 15 April 1996 developing cataract. This risk is modified by age, severity of retinopathy, and duration of the disease. $^{1}$

Some studies have reported that cataract surgery causes progression of retinopathy with new haemorrhages, exudates, and macular oedema, and that progression is associated with poor visual prognosis. ${ }^{2-9}$ It has also been claimed that neovascular glaucoma is common after cataract surgery ${ }^{9-11}$; more often after intracapsular than after extracapsular surgery. ${ }^{11}$ In another study, however, no increase in progression of retinopathy was observed after cataract surgery. ${ }^{12}$ While progression of retinopathy has been shown to be related to the degree of glycaemic control, ${ }^{13}{ }^{14}$ the association between such control and progression of retinopathy after cataract surgery has not been evaluated.

At the Department of Ophthalmology in Helsingborg (population of 145000 ) in southern Sweden, we have offered regular photographic eye examinations to all diabetic patients in the catchment area since 1990. Of the known diabetic population $<75$ years old, approximately $70 \%$ are estimated to have been included. ${ }^{15}$ Patients requiring cataract surgery are taken care of within our own department. Out of the 2232 diabetic patients examined with fundus photography between January 1991 and December 1993 cataract surgery was performed on 77 by four surgeons using similar surgical techniques.

The aim of the present follow up study was to examine the visual acuity 2 years after cataract surgery, and to relate any progression of retinopathy to the degree of glycaemic control, duration of diabetes, and mode of treatment.

\section{Patients and methods}

Seventy seven diabetic patients underwent cataract surgery between January 1991 and December 1993. Among them, 70 were followed up 18-32 months postoperatively. Four of the seven who were not followed up died; two patients were unable to come back for examination because of other diseases; another patient moved from the region and could not be traced.

Forty one patients were on insulin treatment; 29 were treated with oral antihyperglycaemic agents or diet alone. During the study period five of the latter changed to insulin treatment. Nineteen $(27 \%)$ were type 1 diabetic patients, and $51(73 \%)$ type 2 diabetic patients, as decided by the patients' diabetologists. Clinical characteristics are given in

Diabetic patients have an increased risk of Table 1.

In 57 patients the first eye was operated on during the study period. Thirteen patients had previously undergone surgery in one eye. At follow up, a total of 35 patients had been operated on bilaterally, and 35 had been subjected to monocular surgery. We included the first 
Table 1 Clinical characteristics of diabetic patients operated for cataract (mean (SD))

\begin{tabular}{ll}
\hline & $\begin{array}{l}\text { Cataract } \\
\text { surgery group }\end{array}$ \\
\hline Number (male/female) & $70(29 / 41)$ \\
Age at cataract surgery (years) & $70.1(8.2)$ \\
Duration of diabetes at cataract surgery (years) & $18.4(14.9)$ \\
Treatment & \\
Insulin treatment (\%) & 59 \\
Oral treatment (\%) & 30 \\
Diet alone (\%) & 11 \\
Type of diabetes & \\
Type 1 (\%) & 27 \\
Type 2 (\%) & 73 \\
Mean HbA & $7.6(1.5)$ \\
Distribution of retinopathy before surgery & \\
Median (range) & $21(10-70)$ \\
No DR (level 10) (\%) & 43 \\
Mild DR (levels 21-31) (\%) & 27 \\
Moderate to severe NPDR (levels 41-51) (\%) & 7 \\
PDR (60+) (\%) & 23 \\
Macular oedema before surgery (\%) & 14 \\
Macular treatment before surgery (\%) & 21 \\
\hline
\end{tabular}

$\mathrm{DR}=$ diabetic retinopathy; NPDR=non-proliferative diabetic retinopathy; $\mathrm{PDR}=$ proliferative diabetic retinopathy.

operated eye in patients with bilateral surgery during the study period.

Forty eight of the 70 patients included in the present study were participants in the screening programme before surgery, the remaining 22 were enrolled when they were scheduled for cataract surgery. The stage of retinopathy and the prevalence of macular oedema were thus known before surgery from previous photographic examinations in most patients, and were confirmed at a preoperative biomicroscopic examination in all but six patients, who had dense cataracts. In these six patients we used the immediate postoperative examination as our best estimate of presurgery retinopathy level. Results from the biomicroscopic examinations were translated into the alternative classification of the Wisconsin study.

During the 2 year study, surgeons at the department changed technique from extracapsular surgery to surgery with small incision and phacoemulsification. Of the 70 patients, 20 were operated on with the latter technique and 46 with planned extracapsular extraction and posterior chamber implants. Capsular breaks and dialysis caused the implantation of anterior chamber lenses in four patients; vitrectomy was performed in one of these.

EXAMINATION PROCEDURE

A full medical and ocular history was taken before cataract surgery. This included questions on diabetes treatment, use of antihypertensive medication, and duration of diabetes.

A complete ocular examination was also performed initially; this included determination of best corrected visual acuity (Monoyer), tonometry, slit-lamp examination, and retinal biomicroscopy. At follow up the retinopathy level was determined by fundus photography.

\section{FUNDUS PHOTOGRAPHY}

Colour fundus photographs were taken at an angle of $50^{\circ}$ with a Topcon TRC-50 VT fundus camera (Tokyo Optical Co Ltd, Japan). The photographs covered fields $1-3$ of the 7 standard fields, with stereo pairs of the macula (field 2). When retinopathy had been detected, photographs included at least two additional fields. ${ }^{15}$ The alternative classification of the Wisconsin Epidemiologic Study of Diabetic Retinopathy was used to classify the retinopathy level. ${ }^{16}$

Levels of retinopathy were defined as follows ${ }^{16}$ : level 10 , no diabetic retinopathy; level 21 , very mild non-proliferative diabetic retinopathy (NPDR); level 31, mild NPDR; level 41, moderate NPDR; level 51, severe NPDR; level 60, fibrous proliferations only; level 61, panretinal laser treated proliferative diabetic retinopathy (PDR) (no evidence of levels 60 and 65); level 65, PDR without high risk characteristics; level 70, PDR with high risk characteristics. ${ }^{17}$ All levels of PDR were also pooled into one group, $60+$. Furthermore, retinopathy levels were divided into four groups and progression was evaluated; no DR (level 10), mild NPDR (levels 21-31), moderate-severe NPDR (levels 41-51), and PDR (60+).

Macular oedema was defined as the presence of hard exudates and/or retinal thickening within 1 disc diameter of the centre of the macula and was assessed as existent, nonexistent, or questionable, and was in this study considered present, even questionably so.

The photographs were graded in a two step procedure. Intergrader reproducibility was $82 \%$, and intragrader reproducibility varied between $84 \%$ and $88 \%$ about the same level.

The photographic screening examinations were performed on an annual or biennial basis. In this screening programme we also recorded age at diagnosis, mode of treatment, and use of antihypertensive drugs. Best corrected visual acuity was tested with Monoyer charts.

Table 2 Clinical characteristics of patients with and without retinopathy progression following cataract surgery (eyes with $P D R$ at baseline excluded) (mean (SD))

\begin{tabular}{lllll}
\hline & No progression & Progression & $\begin{array}{c}\text { Mean difference }(95 \% \\
\text { confidence interval) }\end{array}$ & $p$ Value \\
\hline Number (male/female) & $24(10 / 14)$ & $30(13 / 17)$ & & \\
Age at cataract surgery (years) & $72.3(6.3)$ & $70.9(8.0)$ & $1.4(-2.5 ; 5.3)$ & 0.49 \\
Duration of diabetes (years) & $9.6(12.4)$ & $17.9(13.1)$ & $8.4(1.3 ; 15.4)$ & 0.02 \\
Type 1 diabetes (\%) & 4 & 23 & $19(2 ; 36)$ & 0.05 \\
Insulin treatment (\%) & 21 & 67 & $46(24 ; 68)$ & 0.001 \\
Mean HbA (\%) $_{\text {Antihypertensive treatment (\%) }}$ & $6.9(1.6)(\mathrm{n}=21)$ & $7.9(1.4)(\mathrm{n}=25)$ & $1.0(0.1 ; 1.8)$ & 0.04 \\
Time at follow up (months) & 38 & 30 & $8(-17 ; 33)$ & 0.56 \\
& $22.4(7.7)$ & $25.2(4.6)$ & $3.0(-0.4 ; 6.4)$ & 0.08 \\
\hline
\end{tabular}


Table 3 Retinopathy before surgery and visual acuity before and after surgery in patients with and without retinopathy progression (eyes with PDR at baseline excluded)

\begin{tabular}{llll}
\hline & No progression & Progression & p Value \\
\hline Number (male/female) & $24(10 / 14)$ & $30(13 / 17)$ & \\
Retinopathy at baseline (median and range) & $10(10-51)$ & $21(10-51)$ & 0.01 \\
Preoperative visual acuity (median and range) & $0.1(<0.1 ; 0.4)$ & $0.1(<0.1 ; 0.4)$ & 0.56 \\
Visual acuity at follow up (median and range) & $0.9(<0.1 ; 1.0)$ & $0.8(<0.1 ; 1.0)$ & 0.19 \\
$\quad \leqslant 0.1$ & $1(4 \%)^{\star}$ & $4(13 \%)$ & \\
$0.2-0.4$ & $1(4 \%)$ & $11(37 \%)$ & \\
$0.5-0.7$ & $8(33 \%)$ & $15(50 \%)$ & \\
$0.8-1.0$ & $14(58 \%)$ & $6(20 \%)$ & 0.23 \\
Macular oedema preoperatively, n (\%) & $2(8 \%)$ & $13(43 \%)$ & 0.0002 \\
Macular oedema postoperatively, $\mathrm{n}(\%)$ & 0 &
\end{tabular}

Data are n (\%), mean (SD); * Total percentages do not add up to 100 because of rounding up or down.

GLYCAEMIC CONTROL

Haemoglobin $A_{1 c}\left(H_{b} A_{1 c}\right.$ was determined by ion exchange chromatography, Mono S-HPLC (non-diabetic range $3.5-5.5 \%) .{ }^{18}$ For each patient we computed the mean of all measurements listed in their hospital records during the 3 years before the follow up examination. The median number of measurements per patient was 7 (range 1-22). There was no significant difference in the number of measurements between the patients whose retinopathy progressed and those who did not.

MAIN OUTCOME MEASURES

The influence of age at surgery, diabetes duration, type of diabetes, mode of treatment, and degree of glycaemic control on progression of retinopathy was assessed by a case-control approach within the cohort. To study if retinopathy progressed more in the eyes which had been operated on than in those which had not, 35 patients with monocular surgery were also examined separately to assess possible asymmetric retinopathy. Patients with PDR at baseline were excluded when progression was estimated.

\section{STATISTICAL METHODS}

The distribution of the different stages of DR and the distribution of visual acuities were compared in eyes with and without retinopathy progression using the Mann-Whitney $\mathrm{U}$ test. To compare age at surgery, duration of

Table 4 Macular oedema, retinopathy, and visual acuity at baseline and at follow up in patients with PDR at baseline

\begin{tabular}{ll}
\hline Number (male/female) & $16(6 / 10)$ \\
Age at cataract surgery (years) & $64.8(9.3)$ \\
Duration of diabetes at surgery (years) & $32.6(10.5)$ \\
Type 1 diabetes (\%) & 69 \\
Panretinal laser treatment before surgery & 94 \\
$\quad(\%)$ & \\
Preoperative retinopathy level (median and & $61(60-70)$ \\
range) & 13 \\
Preoperative macular oedema (\%) & 63 \\
Preoperative macular treatment (\%) & 19 \\
Macular oedema at follow up (\%) & 75 \\
Macular treatment at follow up (\%) & $0.15(<0.1-0.7)$ \\
Preoperative visual acuity (median and & \\
range) & $0.7(<0.1-1.0)$ \\
Visual acuity at follow up (median and & \\
range) & $2(13 \%)$ \\
$\quad \leqslant 0.1$ & $8(50 \%)$ \\
$0.2-0.4$ & $6(37 \%)$ \\
$0.5-0.7$ & $8.1(1.4)$ \\
$0.8-1.0$ & \\
Mean $\mathrm{HbA}_{1 \mathrm{c}}(\%)$ & \\
\hline
\end{tabular}

Data are n (\%), mean (SD). diabetes, and mean $\mathrm{HbA}_{1 \mathrm{c}}$ we used Student's $t$ test; and for the frequencies of type of diabetes, insulin and antihypertensive treatment we used the $\chi^{2}$ test.

\section{Results}

At the baseline examination there were 30 eyes (43\%) without retinopathy, 24 eyes (34\%) with NPDR, and 16 eyes (23\%) with PDR (Table 1). The degree of retinopathy was unchanged in 40 eyes $(57 \%)$ at follow up, had progressed 1-2 levels in 27 eyes (39\%), and 3 levels in three eyes $(4 \%)$.

When progression of retinopathy was evaluated in cataract operated patients without PDR at baseline $(n=54)$, we found that progression was related to a higher average level of $\mathrm{HbA}_{1 \mathrm{c}}(\mathrm{p}=0.04)$, a longer duration of diabetes $(p=0.02)$, a higher prevalence of insulin treatment $(p=0.001)$, and more advanced retinopathy at baseline $(p=0.01)$. The incidence of macular oedema during follow up was higher in patients with retinopathy progression than in those who had not progressed $(p=0.006)$ (Tables 2 and 3$)$. Different techniques of surgery or YAG laser treatment had no influence on the progression of retinopathy.

Patients with PDR at baseline $(n=16)$ had on average $>30$ years' duration of diabetes and most of them were type 1 diabetic patients. All except one had previously had panretinal laser treatment and 10 had received focal laser treatment of the macula. The prevalence of macular oedema was low both at baseline and at follow up (Table 4).

Most patients obtained a significantly better visual acuity (VA) after surgery; 62 patients achieved a VA of 0.5 or better (median 0.8 ; range $0.5-1.0) \quad(p<0.001)$. The remaining eight patients had a VA of 0.2 or less; two of them with moderate to severe NPDR (levels 41 and 51) developed macular oedema with poor vision after surgery. Four of them had been unsuccessfully treated for macular oedema before surgery and had poor vision before the development of cataract. A hemithrombosis occurred 1 year postoperatively in one patient, and another had age-related macular degeneration (Table 5).

The degree of retinopathy in the 35 patients who received monocular surgery was similar in the two eyes at baseline. There were no significant differences with regard to retinopathy progression in the operated and non-operated eyes (Tables 6 and 7).

\section{Discussion}

In our material most of the operated patients achieved good visual acuity and significantly improved vision. The visual acuity after surgery was 0.5 or better in $89 \%$ of eyes.

Our results contrast with those of some other studies, which have shown an increased risk of progression of retinopathy and worsening of vision after cataract surgery. ${ }^{2-9}$ Progression in these studies included an exudative response. Patients with background retinopathy before surgery were at greater risk. ${ }^{23}$ Continuing neo- 
Table 5 Clinical characteristics of patients with poor vision at follow up examination

\begin{tabular}{|c|c|c|c|c|c|c|c|c|c|c|}
\hline Patient & $\begin{array}{l}\text { Age at } \\
\text { surgery }\end{array}$ & Sex & $\begin{array}{l}\text { Preop } \\
\text { VA }\end{array}$ & $\begin{array}{l}\text { Postop } \\
\text { VA }\end{array}$ & Comments & Operative complications & $\begin{array}{l}\text { Preop } \\
\text { ret level }\end{array}$ & $\begin{array}{l}\text { Diab } \\
\text { type }\end{array}$ & Treatment & $\begin{array}{l}\text { YAG } \\
\text { treatment }\end{array}$ \\
\hline A & 85 & $\mathbf{F}$ & 0.1 & 0.1 & $\mathrm{MO}+\mathrm{ARMD}$ & - & 21 & 2 & Insulin & No \\
\hline $\mathbf{B}$ & 81 & $\mathbf{F}$ & 0.4 & $<0.1$ & Hemithrombosis postoperatively & $\begin{array}{l}\text { Fibrin exudation and postop raised } \\
\text { IOP }\end{array}$ & 10 & 2 & Insulin & Yes \\
\hline C & 80 & $\mathbf{F}$ & HM & 0.1 & MO and low vision many years preop & - & 70 & 2 & Insulin & No \\
\hline D & 77 & $\mathbf{F}$ & $\mathrm{CF}$ & 0.2 & $\begin{array}{l}\text { MO, treated preop but worsened postop, } \\
\text { better VA in the non-operated eye }\end{array}$ & $\begin{array}{l}\text { Capsular dialysis and anterior } \\
\text { chamber lens }\end{array}$ & 41 & 2 & Oral & No \\
\hline $\mathbf{E}$ & 76 & $\mathbf{F}$ & $<0.1$ & 0.1 & $\begin{array}{l}\text { MO worsened postop, better VA in the } \\
\text { non-operated eye }\end{array}$ & - & 51 & 2 & Oral & No \\
\hline $\mathbf{F}$ & 71 & $\mathbf{F}$ & $\mathbf{P}$ & HM & Venous thrombosis several years earlier & - & 51 & 2 & Oral insulin & No \\
\hline G & 66 & $\mathbf{F}$ & CF & $\mathrm{CF}$ & MO and low vision many years preop & - & 31 & 1 & Insulin & No \\
\hline $\mathbf{H}$ & 66 & $\mathbf{F}$ & $\mathrm{CF}$ & CF & $\begin{array}{l}\text { MO and PDR preop, MO worsened } \\
\text { postop }\end{array}$ & - & 70 & 2 & Insulin & No \\
\hline
\end{tabular}

ARMD = age-related macular degeneration; $P=$ light perception; $H M=$ hand movements; $C F=$ counting fingers; $M O=$ macular oedema; YAG laser treatment for capsular opacification.

Table 6 Distribution of retinopathy in operated eye at baseline and at follow up in 35 monocularly operated patients

\begin{tabular}{|c|c|c|c|c|c|}
\hline & \multicolumn{5}{|l|}{ Follow up } \\
\hline & No DR (level 10) & $\begin{array}{l}\text { Mild NPDR } \\
\text { (levels 21-31) }\end{array}$ & $\begin{array}{l}\text { Moderate/severe NPDR } \\
\text { (levels 41-51) }\end{array}$ & PDR (level 60+) & Total \\
\hline \multicolumn{6}{|l|}{ Baseline } \\
\hline No DR & $12(34)$ & $8(23)$ & & & $20(57)$ \\
\hline Mild NPDR & & $3(9)$ & $2(6)$ & $1(3)$ & $6(17)$ \\
\hline Moderate/severe NPDR & & & $3(9)$ & $1(3)$ & $4(11)$ \\
\hline PDR & & & & $5(14)$ & $5(14)$ \\
\hline Total & $12(34)$ & $11(31)$ & $5(14)$ & $7(20)$ & $35(100)^{\star}$ \\
\hline
\end{tabular}

$\mathrm{DR}=$ diabetic retinopathy; NPDR=non-proliferative diabetic retinopathy; $\mathrm{PDR}=$ proliferative diabetic retinopathy.

Data are n (\%); * total percentages do not add up to 100 because of rounding up or down.

vascularisation was a threat to vision. ${ }^{7}$ Old age predicted low postoperative visual acuity in one previous study. ${ }^{9}$ The degree of glycaemic control, a known risk factor for retinopathy progression, ${ }^{13}$ was not reported in these studies.

In the current study neither patients without retinopathy nor patients with treated PDR experienced severe retinopathy progression after cataract surgery. Patients with PDR had a very long diabetes duration and all except one had been treated with panretinal photocoagulation and had quiescent PDR. Most of the patients were focally treated for macular oedema. Despite previous macular and panretinal treatment, the majority $(87 \%)$ obtained a postoperative visual acuity of 0.5 or better (Table 4). This is in contrast with the poor visual prognosis reported in patients with PDR in a previous study. ${ }^{8}$ The postoperative visual acuity in that study was better, however, in those with quiescent than in those with active PDR with visual acuity $20 / 40$ or better in $52 \%$ of patients in the former group. In our study, low visual acuity at follow up in patients with PDR was related to the preoperative retinal state, although in one patient $(\mathrm{H})$ the macular oedema worsened (Table 5).

The rate of retinopathy progression was similar in the two eyes of patients undergoing monocular surgery (Tables 6 and 7). In two patients with unilateral surgery and background retinopathy, however, there was deterioration of the macular oedema and these patients ( $D$ and $E$ ) ended up with worse vision in the operated eye than in the eye which had not been operated on (Table 5).

Four of the eight patients with low postoperative visual acuity achieved some visual improvement, and none experienced severe postoperative complications (Table 5). Thus, cataract surgery may have given useful improvement of the visual acuity also in this group of patients. One patient in this group (H) had cataract surgery in order to improve the possibility of completing the panretinal treatment. Cataract surgery has been a recommended therapy when lenticular opacity prevents treatment. ${ }^{19}$ A long history of macular oedema or venous thrombosis, such as in cases $F$ and $G$, was associated with bad postoperative visual function, a fact that should be kept in mind if cataract surgery is considered (Table 5).

Table 7 Distribution of retinopathy in non-operated eye at baseline and at follow up in 35 monocularly operated patients

\begin{tabular}{|c|c|c|c|c|c|}
\hline & \multicolumn{5}{|l|}{ Follow up } \\
\hline & No DR (level 10) & $\begin{array}{l}\text { Mild NPDR } \\
\text { (levels 21-31) }\end{array}$ & $\begin{array}{l}\text { Moderate/severe NPDR } \\
\text { (levels 41-51) }\end{array}$ & PDR (level 60+) & Total \\
\hline \multicolumn{6}{|l|}{ Baseline } \\
\hline No DR & $11(31)$ & $8(23)$ & $1(3)$ & & $20(57)$ \\
\hline $\begin{array}{l}\text { Mild NPDR } \\
\text { Moderate/severe NPDR }\end{array}$ & & $5(14)$ & $4(11)$ & $1(3)$ & $\begin{array}{l}5(14) \\
5(14)\end{array}$ \\
\hline PDR & & & & $5(14)$ & $5(14)$ \\
\hline Total & $11(31)$ & $13(37)$ & $5(14)$ & $6(17)$ & $35(100)^{\star}$ \\
\hline
\end{tabular}

$\mathrm{DR}=$ diabetic retinopathy; NPDR=non-proliferative diabetic retinopathy; $\mathrm{PDR}=$ proliferative diabetic retinopathy.

Data are $n(\%)$; total percentages do not add up to 100 because of rounding up or down 
In our study, progression of retinopathy following cataract surgery was significantly related to degree of glycaemic control as assessed by the average level of $\mathrm{HbA}_{1 \mathrm{c}}$ before surgery and during the follow up period. Progression was also related to presence of retinopathy at baseline, duration of diabetes, and insulin treatment. These risk factors for retinopathy progression are in accordance with those found in other studies. ${ }^{141620}$ The findings of our study should be interpreted cautiously because of the small number of patients and the short follow up time. It is plausible, however, that the glycaemic level and the presence of retinopathy at baseline also influenced the progression of retinopathy in this group of patients subjected to cataract surgery, but other pathogenic mechanisms may have been operational as well. It is well known that cystoid macular oedema (CMO) may occur postoperatively in cataract operated eyes. Inflammatory mediators may play a role, as they cause a breakdown of the blood-retinal barrier. ${ }^{21} \mathrm{~A}$ higher postoperative frequency of CMO has been reported in eyes of diabetic patients, even in those without retinopathy. ${ }^{22}$ Breakdown of the bloodretinal barrier is also an early sign of diabetes induced changes in the retina. ${ }^{23}$ The factors contributing to the breakdown of the bloodretinal barrier and causing macular oedema after cataract surgery in non-diabetic eyes could possibly act synergistically with factors that cause breakdown of the blood-retinal barrier in background diabetic retinopathy. This might cause retinopathy to progress after cataract surgery.

Some studies have reported an increased incidence of neovascular glaucoma and continuing retinal neovascularisation following cataract surgery. ${ }^{9-11}$ This was not observed in any of our patients.

It should be emphasised that the present study, like most similar studies, was based on a small number of patients. While our results are encouraging, a larger study with a longer follow up time could provide more conclusive data. Results from the preoperative examination might have been less reliable because of the obscuring cataract. In the two eyes of patients with monocular surgery, however, the retinopathy levels were very similar. Patients were randomly allocated to different examiners at follow up, and hence we have no reason to believe that there was a systematic error in the evaluation of the postoperative visual acuity or in the grading of photographs.

One might conclude that in the current study visual prognosis after cataract surgery was good. Those patients whose retinopathy progressed most had background retinopathy and poorer glycaemic control. It is possible that these factors in conjunction with the trauma of surgery in some patients caused the increased progression of retinopathy after cataract surgery.

Our screening programme covered most patients, many of them elderly. Thus, most patients with vision threatening retinopathy and a need for laser treatment, whether focal or panretinal, had received this at the time when cataract surgery was performed. This may be the reason why few diabetic patients in the present study had poor visual outcome after cataract surgery. This study was supported by the Gorthon and Zoéga Foundations, Helsingborg, HSF (Rådet for hälso-och sjukvårdsforskning i södra Sverige), Järnhardts Foundation Malmö, Research Funds at the Malmö University Hospital and
Kronprinsessan Margaretas Arbetsnämnd for Synskadade Kronprinsessan Margaretas Arbetsnämnd för Synskadade
(MH), and by an unrestricted grant from Alcon Research Institute $(\mathrm{AH})$.

1 Klein BEK, Klein R, Moss SE. Prevalence of cataracts in a population-based study of persons with diabetes mellitus. Ophthalmology 1985;92:1191-6.

2 Jaffe GJ, Burton TC. Progression of non-proliferative diabetic retinopathy following cataract extraction. Arch Ophthalmol 1988;106:745-9.

3 Pollack A, Dotan S, Oliver M. Progression of diabetic retinopathy after cataract extraction. Br $\mathcal{F}$ Ophthalmol 1991;75: 547-51.

4 Pollack A, Dotan S, Oliver M. Course of diabetic retinopathy following cataract surgery. $\mathrm{Br} f \mathcal{O}$ Ophthalmol 1991;75:2-8

5 Schatz H, Atienza D, Mc Donald HR, Johnson RN. Severe diabetic retinopathy after cataract surgery. $A m \mathcal{F}$ Ophthalmol 1994;117:314-21.

6 Pollack A, Leiba H, Bukelman A, Oliver M. Cystoid macular oedema following cataract extraction in patients with diabetes. Br F Ophthalmol 1992;76:221-4.

7 Cunliffe IA, Flanagan DW, George NDL, Aggarwaal RJ, Moore AT. Extracapsular cataract surgery with lens implanotion in diabetics with and without proliferative retinnation in diabetics with and without
opathy. Br $\mathscr{f}$ Ophthalmol 1991;75:9-12.

8 Hykin PG, Gregson RMC, Stevens JD, Hamilton AMP. Extracapsular cataract extraction in proliferative diabetic retinopathy. Ophthalmology 1993;100:394-9.

9 Benson WE, Brown GC, Tasman W, McNamara JA, Vander JF. Extracapsular cataract extraction with placement of a posterior chamber lens in patients with diabetic retinopathy. Ophthalmology 1993;100:730-8.

10 Aiello LM, Wand M, Liang G. Neovascular glaucoma and vitreous hemorrhage following cataract surgery in patients vitreous hemorrhage following cataract surgery in pa

11 Poliner LS, Christianson DJ, Escoffery RF, Kolker AE, Gordon ME. Neovascular glaucoma after intracapsular and extracapsular cataract extraction in diabetic patients. Am $\mathcal{f}$ Ophthalmol 1985;100:637-43.

12 Sebestyen JG. Intraocular lenses and diabetes mellitus. $A m \mathcal{F}$ Ophthalmol 1986;101:425-8.

13 The Diabetes Control and Complications Trial Research Group. The effect of intensive treatment of diabetes on the development and progression of long-term complications in insulin-dependent diabetes mellitus. $N$ Engl F Med 1993; 329:977-86.

14 Klein R, Klein BEK, Moss SE, Cruickshanks KJ. Relationship of hyperglycemia to the long-term incidence and proship of hyperglycemia to the long-term incidence and progression of

15 Henricsson M, Nilsson A, Groop L, Heijl A, Janzon L. Prevalence of diabetic retinopathy in relation to age at onset, treatment, duration and glycemic control. [Abstract] In Proceedings of the XXXII Nordic Congress of Ophthalmology in Odense, 1995.

16 Klein R, Klein BEK, Moss SE, Davis MD, DeMets DL. The Wisconsin epidemiologic study of diabetic retinopathy IX. Four-year incidence and progression of diabetic retinFour-year incidence and progression of diabetic retinopathy when age at diagnosis
Ophthalmol 1989;107:237-43.

17 Diabetic Retinopathy Study Research Group: Report VII. A modification of the Airlie House classification of diabetic retinopathy. Invest Ophthalmol Vis Sci 1981;21:210-26.

18 Jeppsson JO, Jerntorp P, Sundkvist G, Englund H, Nylund $V$. Measurement of hemoglobin $A_{1 c}$ by a new liquidchromatographic assay: methodology, clinical utility, and relation to glucose tolerance evaluated. Clin Chem 1986;32: 1867-72.

19 Edwards MG, Schachat AP, Bressler SB, Bressler NM. Outcome of cataract operations performed to permit diagnosis, to determine eligibility for laser therapy, or to perform laser therapy of retinal disorders. Am $₹$ Ophthalmol 1994;118: therapy

20 Klein R, Klein BEK, Moss SE, Cruickshanks KJ. The Wisconsin Epidemiologic Study of Diabetic Retinopathy XIV. Ten-year incidence and progression of diabetic retinopathy. Arch Opththalmol 1994;112:1217-28.

21 Stern AL, Taylor DM, Dalburg LA, Cosentino RT. Pseudophakic cystoid maculopathy. A study of 50 cases. Ophthalmology 1981;88:942-6.

22 Menchini U, Bandello F, Brancato R, Camesasca FI, Galdini $M$. Cystoid macular oedema after extracapsular cataract extraction and introcular lens implantation in diabetic patients without retinopathy. $\mathrm{Br} f$ Ophthalmol 1993;77:208-11.

23 Cunha-Vaz JG. Studies on the pathophysiology of diabetic retinopathy. The blood-retinal barrier in diabetes. Diabetes 1983;32(suppl 2):20-7. 